Gut, 1980, 21, 570-573

\title{
Prospective comparison of two Sengstaken tubes in the management of patients with variceal haemorrhage
}

\author{
K MITCHELL,* D B A SILK, $†$ AND ROGER WILliaMS \\ From the Liver Unit, King's College Hospital and Medical School, London
}

SUMmARY To compare the efficacy of two oesophageal tamponade tubes, 28 patients with endoscopically proven actively bleeding varices were randomly allocated to be intubated with either a newly available 4-lumen tube incorporating an extra lumen for oesophageal suction, or the modified 3-lumen Sengstaken tube. The patients and the nursing staff preferred using the 4-lumen tube and both aspiration pneumonias and balloon dysfunction occurred less frequently. Variceal haemorrhage was successfully controlled for the first 12 hours in most patients in the two treatment groups, although the incidence of re-bleeding at 48 hours after the tube had been deflated was high.

Variceal haemorrhage is a life-threatening problem in patients with portal hypertension, and, despite the absence of controlled data, most clinicians would consider that oesophageal tamponade with the Sengstaken-Blakemore tube remains the most reliable non-surgical means of immediately controlling the bleeding. ${ }^{2}$ While oesophageal ulceration and pulmonary aspiration of gastric contents and saliva are serious complications of oesophageal tamponade, ${ }^{3}$ they can be minimised by limiting the duration of tamponade to approximately 24 hours, ${ }^{4}$ by avoiding traction and by adding a fourth lumen for continuous pharyngeal suction. ${ }^{5}$ Our experience, however, has shown that such complications still occur despite these safety measures and the close supervision by trained staff in a specialist unit. Recently a new oesophagogastric tamponade tube has become available to aid aspiration of pharyngeal collections of fluid and in this paper we report the results of a prospective trial designed to compare the efficacy of this tube with that of the modified 3-lumen Sengstaken tube previously used. Particular emphasis has been placed upon comparing ease of intubation, patient tolerance, and problems of tube management.

*Present address: Department of Medicine, Royal Brisbane Hospital, Queensland, Australia.

†Present address: Gastroenterology Unit, Central Middlesex Hospital, London NW10.

Received for publication 15 January 1980

\section{Methods}

The two tubes studied were the 3-lumen Sengstaken tube (Franklin \& Sons Ltd, High Wycombe, Bucks, UK) modified according to Boyce ${ }^{5}$ by tying a 14gauge nasogastric tube to open immediately proximal to the oesophageal balloon, and the Minnesota 4-lumen oesophagogastric tamponade tube (Davol International Limited, Clacton-on-Sea, Essex UK).

\section{PATIENTS}

Twenty-eight consecutive patients with endoscopically proven active variceal haemorrhage ${ }^{6}$ took part in the trial and were randomly allocated for treatment with one of the two Sengstaken tubes. Six of the 14 patients treated with the 4-lumen tube and four of the 14 patients treated with the 3-lumen tube also received triglycyl hormonogen of lysinevasopressin intravenously in a dose of $2 \mathrm{mg}$ fourhourly for five days. ${ }^{7}$ The two groups of patients were equally matched with respect to age, sex, and initial clinical grading according to the modified Child's classification by Pugh et al. ${ }^{8}$ (Table 1). Hepatic cirrhosis was the basis of the portal hypertension in 27 of the 28 patients, while in the one remaining patient the cause was portal vein thrombosis.

INTUBATION TECHNIQUE

Patients were intubated perorally in either the left lateral position (usually) or sitting up, with con- 
Table 1 Data relating to patient groups and duration and complications of intubation

\begin{tabular}{|c|c|c|}
\hline & 4-lumen tube & $\begin{array}{l}\text { Modified } \\
\text { 3-lumen tube }\end{array}$ \\
\hline $\begin{array}{l}\text { Age }(\mathrm{yr}) \text { (mean } \pm \text { SD) } \\
\text { Clinical grading before intubation: }\end{array}$ & $46 \cdot 2 \pm 12 \cdot 2$ & $49 \cdot 3 \pm 13 \cdot 4$ \\
\hline $\begin{array}{l}\text { Grade B } \\
\text { Grade C }\end{array}$ & $\begin{array}{l}6(42.9 \%) \\
8(57 \cdot 1 \%)\end{array}$ & $\begin{array}{r}4(28.6 \%) \\
10(71.4 \%)\end{array}$ \\
\hline \multicolumn{3}{|l|}{$\begin{array}{l}\text { Duration of intubation }(\mathrm{h}) \\
\text { (median + range): }\end{array}$} \\
\hline $\begin{array}{l}\text { Both balloons inflated } \\
\text { Gastric balloon only }\end{array}$ & $\begin{array}{l}24(24-45) \\
48(45-71)\end{array}$ & $\begin{array}{l}24(5-30)^{*} \\
48(5-63)\end{array}$ \\
\hline Difficulty of intubation & 4 & 0 \\
\hline Dysfunction of gastric balloont & 1 & 3 \\
\hline Leaking of oesophageal balloon & 0 & 3 \\
\hline Pulmonary aspiration & 1 & 5 \\
\hline Patient intolerance $\ddagger$ & $\mathbf{0}$ & $6(P<0.05)$ \\
\hline
\end{tabular}

* Two early deaths, at five and 11 hours.

tLeaking of more than $50 \%$ of gastric balloon contents or gastric balloon obstructed in inflated position.

$\ddagger$ Premature removal and/or sedation necessitated.

tinuous pharyngeal suction and without topical pharyngeal anaesthesia in order to minimise the risk of pulmonary aspiration. At the outset of the trial it was found that the almost inevitable retching caused the softer and more pliable 4-lumen tube to be regurgitated during attempts at intubation and it was found necessary to stiffen this tube by passing an introducer down the gastric aspirate lumen. Endoscopic biopsy forceps, angiographic catheter guide wire, and nylon wire were tried as introducers. The latter proved the best and the wire was withdrawn immediately after successful intubation. The gastric balloon of the 3-lumen tube was inflated with $150 \mathrm{ml}$ of a mixture of water and Hypaque (to assist visualisation on radiography of the chest), while that of the 4-lumen tube was inflated with $500 \mathrm{ml}$ of air. Both were then pulled gently but firmly onto the cardio-oesophageal junction and secured at the angle of the mouth with Elastoplast. Finally, the oesophageal balloons were inflated with air to a pressure of $40 \mathrm{mmHg}$. After intubation, a radiograph of the chest was taken to confirm that the tubes were correctly positioned. Nursing care of the patient included aspiration of gastric contents and the checking of oesophageal balloon pressure at hourly intervals. To avoid ulceration at the angle of the mouth, the tubes were moved from one side of the mouth to the other every two hours.

\section{ASSESSMENT OF BLEEDING}

Treatment was considered successful when vital signs improved in the absence of a reaccumulation of blood in aspirated gastric contents, and with a stable haemoglobin level. Persistent fresh melaena, a falling haemoglobin level, and aspiration of more than $50 \mathrm{ml}$ of fresh blood from either stomach or oesophagus were taken as criteria for active bleeding. In the patients in whom bleeding was controlled, the oesophageal balloon was deflated after 24 hours and the gastric balloon was left inflated and maintained in position for another 24 hours. If control of bleeding was maintained at the end of this period the gastric balloon was deflated and the tube removed. When bleeding was not controlled the patients were treated by inserting the tube again or by other measures; in neither instance did they remain in the trial.

\section{Results}

\section{CONTROL OF BLEEDING}

Initial control of bleeding was achieved in a high proportion of patients once the tubes were correctly positioned (Table 2). Only one of the 14 patients continued to bleed after intubation with the 3-lumen tube. The first two patients randomised to the 4lumen tube group had to be withdrawn from the trial because of failure of intubation as described later, but, of the 12 remaining patients, only one continued to bleed and in this patient haemorrhage was subsequently arrested when the tube was repositioned and treatment with glypressin and vasopressin instituted.

As Table 2 shows, bleeding was successfully controlled for the first 12 hours in most patients of both treatment groups. By 24 hours, however, a total of six patients in the 4-lumen tube group and four patients with the 3-lumen tube had re-bled, and by 48 hours at least half the patients in each group had sustained another variceal haemorrhage. Examination of the survival figures for that hospital ad-

Table 2 Summary of control of bleeding

\begin{tabular}{|c|c|c|c|c|c|c|c|c|}
\hline \multirow[t]{2}{*}{ Control of bleeding } & \multicolumn{4}{|l|}{ A-lumen tube } & \multicolumn{2}{|l|}{ 3-lumen tube } & \multirow{2}{*}{\multicolumn{2}{|c|}{$\underset{(\text { no. })}{\text { Total }}(\boldsymbol{n}=14$}} \\
\hline & $\begin{array}{l}\text { Tube alone } \\
(n=8)\end{array}$ & $\begin{array}{l}\text { Tube- } \\
\text { glypressin } \\
(n=6)\end{array}$ & $\begin{array}{l}\text { Total } \\
\text { (no.) }\end{array}$ & $\begin{array}{c}(n=14) \\
(\%)\end{array}$ & $\begin{array}{l}\text { Tube alone } \\
(n=10)\end{array}$ & $\begin{array}{l}\text { Tube }+ \\
\text { glypressin } \\
(n=4)\end{array}$ & & \\
\hline $\begin{array}{l}\text { Initial } \\
\text { For } 12 \mathrm{~h} \\
\text { For } 24 \mathrm{~h} \\
\text { For } 48 \mathrm{~h}\end{array}$ & $\begin{array}{l}6 \\
6 \\
5 \\
4\end{array}$ & $\begin{array}{l}6 \\
5 \\
3 \\
3\end{array}$ & $\begin{array}{r}12 \\
11 \\
8 \\
7\end{array}$ & $\begin{array}{l}85 \cdot 7 \\
78 \cdot 6 \\
57 \cdot 1 \\
50\end{array}$ & $\begin{array}{l}9 \\
8 \\
2 \\
2\end{array}$ & $\begin{array}{l}4 \\
3 \\
3 \\
3\end{array}$ & $\begin{array}{r}13 \\
11 \\
10 \\
5\end{array}$ & $\begin{array}{l}92 \cdot 9 \\
75 \cdot 6 \\
71 \cdot 4 \\
35 \cdot 7\end{array}$ \\
\hline
\end{tabular}


mission, whether considered overall or separately according to the clinical grades, showed no statistically significant difference between the 4- and 3lumen tube groups.

COMPLICATIONS OF INTUBATION (Table 1) All patients found oesophageal tamponade uncomfortable. Significant intolerance necessitating removal of the tube and/or sedation as well as associated aspiration occurred in six patients intubated with the 3-lumen tube. Treatment with the 4-lumen tube was not associated with this degree of intolerance, a difference which was statistically significant $\left(\chi^{2}=5 \cdot 30, P<0.05\right)$.

Intubation with the 3-lumen tube was free from difficulties, but there were problems on four occasions with the 4-lumen tube. During intubation of the first two patients an introducer was not used and the procedure failed. On two other occasions intubation had to be repeated because the introducer could not be withdrawn, although the tube was positioned correctly. No other problems were encountered once the 0.048 inch diameter nylon guide wire was routinely used as the introducer.

Gastric balloon dysfunction occurred in only one patient treated with the 4-lumen tube and was found to have been caused by blockage of the gastric balloon lumen. With the 3-lumen tube, leakage of at least $50 \%$ of the balloon contents occurred on three occasions. Oesophageal balloon pressure in the 4-lumen tube remained stable throughout, but it was usual for the oesophageal balloon pressure in the 3-lumen tube to decrease by $5-10 \mathrm{mmHg} / \mathrm{h}$. In three patients a pressure drop of more than $10 \mathrm{mmHg} / \mathrm{h}$ was observed and in each case this was associated with rebleeding.

The specific complication of pulmonary aspiration was found on six occasions with the development of coarse basal crepitations and radiological changes. In one case, the abnormalities were severe enough to merit use of the term 'shock lung syndrome'. As far as could be determined, aspiration occurred after intubation and in each case was associated with obvious choking or retained secretions. Five out of the six episodes occurred in association with the 3-lumen tube, including the one case of 'shock lung syndrome'.

\section{Discussion}

As the purpose of the study was to compare the efficacy of the two types of oesophageal tamponade tubes, we were initially biased against the softer and more pliable 4-lumen tube because of the difficulties encountered during the intubation procedure. Once the problems were overcome by using an introducer wire, it became apparent to us that the 4-lumen tube has certain advantages over the modified 3-lumen tube. First and foremost, the patients tolerated this better, almost certainly because the tube is made of softer, more pliable rubber with smoother balloonto-tube mouldings. Incorporation of the oesophageal aspiration lumen into the tube also resulted in a more comfortable product. The lower frequency of dysfunction, particularly deflation, which occurred with the 4-lumen tube, was also likely to be due to the better moulding of the balloons to the tube. Nursing staff preferred the 4-lumen tube because the different lumens were clearly labelled and aspiration of the oesophageal secretions was easier. Furthermore, pulmonary aspiration occurred less often in the patients who had been intubated with the 4- rather than with the modified 3-lumen tube. Again, the reason for this is the better aspiration of pharyngeal and oesophageal secretions obtained with this type of tube.

Although the overall results of oesophageal tamponade were encouraging in that bleeding was controlled for 12 hours in most of the patients, the results highlight the point that oesophageal tamponade has to be considered at best as an early link in a planned chain of therapeutic events as an increasing number of patients re-bled between 12 and 48 hours after intubation. Patients who received glypressin as well as oesophageal tamponade appeared to fare better than those treated with tamponade alone and a controlled study is currently in progress to assess the validity of this suggestion.

We are indebted to the Sisters and the nursing staff who contributed greatly to the care of these patients. The generous assistance of Davol Ltd is also gratefully acknowledged.

\section{References}

'Pitcher JL. Safety and effectiveness of the modified Sengstaken-Blakemore tube: a prospective study. Gastroenterology 1971; 61: 291-8.

${ }^{2}$ Teres J, Cecilia A, Bordas JM, Romola A, Bru C, Rodes J. Esophageal tamponade for bleeding varices. Controlled trial between the Sengstaken-Blakemore tube and the Linton-Nachlas tube. Gastroenterology 1975; 75: 566-9.

${ }^{3}$ Conn HO. Sengstaken-Blakemore tube revisited. Gastroenterology 1971; 61 : 398-400.

${ }^{4}$ Read AE, Dawson AM, Kerr DNS, Turner MD, Sherlock S. Bleeding oesophageal varices treated by oesophageal compression tube. Br Med J 1960; 1: 227-31.

${ }^{5}$ Boyce HW. Modification of the Sengstaken-Blakemore balloon tube. $N$ Engl J Med 1960; 267: 195-6.

${ }^{6}$ Mitchell KJ, Macdougall BRD, Silk DBA, Williams R. Importance of repeated endoscopy in determining the 
source of haemorrhage in portal hypertension. (Abstract.) Gut 1978; 19: A955-A6.

${ }^{7}$ Vosmik J, Jedlicka K, Mulder JL, Cort JH. Action of the triglycyl hormonegen of vasopressin (glypressin) in patients with liver cirrhosis and bleeding esophageal varices. Gastroenterology 1977; 72: 605-9.

${ }^{8}$ Pugh RNH, Murray-Lyon IM, Dawson JL, Pietroni MC, Williams R. Transection of the oesophagus for bleeding oesophageal varices. Br J Surg 1973; 60: 646-9. 